\title{
Components of Stroop-like interference in picture naming
}

\author{
WIDO LA HEIJ \\ University of Leiden, Leiden, The Netherlands
}

\begin{abstract}
The semantic interference effect observed in Stroop tasks and picture-word interference tasks might be due to the previous confounding of semantic similarity with task relevance (in the Stroop task) and with perceptual similarity (in the picture-word interference task). A picture-word variant of the Stroop task was devised in which the factors of task relevance and perceptual similarity were controlled. The distractor conditions allowed for the examination of four types of context effects. The results show that the overall Stroop-like interference effect can be decomposed into interference effects due to (1) a semantic relation between distractor and target, (2) the semantic relevance of the distractor word in the task at hand, (3) the presence of the distractor word in the response set, and (4) the mere presence of a word. Implications of these findings for the locus or loci of Stroop and picture-word interference effects are discussed. It is concluded that distractor words in Stroop-like naming tasks interfere mainly in the process of name retrieval.
\end{abstract}

In the Stroop task, subjects are required to name colors that are part of, or accompanied by, a printed word (see, e.g., Glaser \& Glaser, 1982; Stroop, 1935); in the picture-word interference task, subjects are required to name pictures that are accompanied by a printed word (see, e.g., Rosinski, Golinkoff, \& Kukish, 1975; Underwood, 1976). In the Stroop task (see, e.g., Fox, Shor, \& Steinman, 1971; Klein, 1964), and in the picture-word interference task (see, e.g., Glaser \& Düngelhoff, 1984; Guttentag \& Haith, 1978; Lupker, 1979; Rosinski, 1977), a distractor word that is semantically related to the target seems to induce more interference than a distractor word that is unrelated to the target. This semantic interference effect stands in marked contrast to the semantic facilitation effect observed in tasks in which subjects are required to read a target word that is preceded by, or presented simultaneously with, a prime word (e.g., Dallas \& Merikle, 1976; La Heij, Van der Heijden, \& Schreuder, 1985; Warren, 1977).

A conclusion that could be drawn from these results is that a semantic relation between a distractor word (or prime word) and a target will hamper performance in tasks in which nonverbal targets have to be named (as in the Stroop task and the picture-word interference task) but will facilitate performance in tasks in which verbal targets have to be read (as in the word-reading variant of the semantic priming task). Before accepting such a conclusion, it would seem worthwhile to determine whether the discrepancy can be attributed to other characteristics of the various tasks.

Further inspection of the Stroop task and the pictureword interference task reveals that in both of these tasks the semantic relatedness factor is confounded with another

Requests for reprints should be sent to W. La Heij, Department of Psychology, Unit of Experimental Psychology, University of Leiden, Hooigracht 15, 2312 KM Leiden, The Netherlands. factor that might be responsible for the interference effects observed. Neumann (1980) and La Heij et al. (1985) argued that the effect of a semantic relation between the word and the color in the Stroop task is confounded with the relevance of the word in the task at hand. Neumann (1980) argued that the longer mean response latency obtained in a condition in which, for example, the word BLUE is presented in red ink than in a condition in which the word FRIEND is presented in red ink (see Klein, 1964) could be due either to the fact that the word BLUE bears a semantic relation to the color red or to the fact that the word BLUE is highly relevant in a task in which subjects are instructed to name colors.

To disconfound semantic similarity and task relevance, Neumann (1980) combined the orthodox color-word variant of the Stroop task with a dot-counting variant, in which a number of dots was accompanied by an incongruent numeral. All orthogonal combinations of the two kinds of target (color patches and series of dots) and the two kinds of distractor (color names and numerals) were presented. The effect of, for example, the word RED on the naming of the color blue was compared with the effect of the word FOUR on the naming of the color blue. The words RED and FOUR were equally relevant in the task, because both belonged to one of the target categories. The results showed a small but significant semantic facilitation effect; that is, an incongruent color word appeared to facilitate the naming of an accompanying color, compared to a numeral. Neumann (1980) concluded that the semantic interference effect observed in the Stroop task is indeed due to a confounding of the semantic relatedness and task relevance factors. A similar conclusion was reached by La Heij et al. (1985) on the basis of experiments with word-word variants of the Stroop task.

This account of the semantic interference effect in the Stroop task cannot explain, however, the semantic interference effect observed in the picture-word interference 
task. In this paradigm, the targets are often chosen from a large number of semantic categories, and, as a consequence, the task relevance of a distractor word is not well defined (subjects probably consider each name of an object as a potential response).

Neumann and Kautz (1982) argued that the semantic interference effect observed in picture-word interference studies might be due to a confounding of the factors of semantic relatedness and perceptual similarity between the target picture and the object denoted by the distractor word. For example, the fact that the word CAT induces a larger amount of interference on the naming of the picture of a dog than does the word CAR can be due either to the semantic similarity between the distractor and the target or to the perceptual similarity between the pictures of dogs and cats. Because of this perceptual similarity, it could take more time to identify the picture when the distractor word suggests an incorrect interpretation of the four-footed animal depicted.

Neumann and Kautz (1982) tested this hypothesis. Four pictures were selected from each of two semantic categories, clothes and animals. The pictures were drawn such that the contours of each exemplar of one category were very similar to the contours of one of the exemplars of the other category (e.g., the picture of a mouse was similar to the picture of a shoe). The results supported the hypothesis: the longest picture-naming latencies and the largest number of errors were obtained when a target picture was accompanied by a word that denoted a visually similar exemplar from the alternative semantic category. For example, the naming of the picture of a shoe was hampered by the presence of the word MOUSE.

The results of two other studies seem to corroborate this finding. First, Palmer (1975) presented target pictures that were preceded by an appropriate or inappropriate contextual scene. In one of the conditions, the target was visually very similar to an object that could be expected on the basis of the preceding context. For example, the picture of a mailbox, visually very similar to the picture of a loaf of bread, followed a kitchen-counter scene. The largest number of misidentifications were observed in this condition, which suggests that the context primed an incorrect interpretation of the somewhat ambiguous target picture.

Second, in a face-name interference task, Young, Ellis, Flude, McWeeny, and Hay (1986) showed that the naming times of photographs of familiar politicians and pop stars were larger when the distractor word was the name of a person from the same occupational category than when the distractor word was the name of a person from a different occupational category. The results of their third experiment, however, showed that this semantic category effect was due to the similar appearance of people in the same occupational category, and not to category membership per se. The conclusion that can be drawn from the results of the studies of Neumann and Kautz (1982), Palmer (1975), and Young et al. (1986) is that at least part of the semantic interference effect reported in picture-word interference studies probably can be attributed to a perceptual interference effect.

The present study had a number of objectives. The first one was to determine the effect of a semantic relation between the distractor word and the target in a picture-word variant of the Stroop task, controlling for task relevance and perceptual similarity. The second objective was to determine the contribution of three other distractor characteristics to the overall interference effect: (1) the relevance of the distractor word in the task at hand, (2) the presence of the distractor word in the set of possible responses, and (3) the use of a word or a nonword (a series of Xs) as the distractor.

\section{EXPERIMENT 1}

To disconfound the semantic similarity and semantic relevance factors in a Stroop-like task, the number of relevant semantic categories should be increased from one (color in the Stroop task) to two. In Experiment 1, target pictures were chosen from two semantic categories, tools and musical instruments (see Figure 1). The experimental design was similar to the design used by Neumann (1980) in which six different distractor conditions could be distinguished (see Figure 2).

In the first condition, the distractor was the verbal label of one of the other pictures from the same semantic category (e.g., the picture of a trumpet with the word GUITAR). This condition will be referred to as REL/RS (related/in response set; i.e., the word was related to the picture and was part of the response set). In the second condition, the distractor was the verbal label of one of the pictures in the alternative target category (e.g., the picture of a trumpet with the word HAMMER). This condition will be referred to as UNR/RS (unrelated/in response set; i.e., the word was unrelated to the picture but was part of the response set). In the third condition, the distractor denoted a member of the picture's semantic category that was not one of the targets in the experiment (e.g., the picture of a trumpet with the word VIOLIN). This condition will be referred to as REL/NRS (related/not in response set; i.e., the word was related

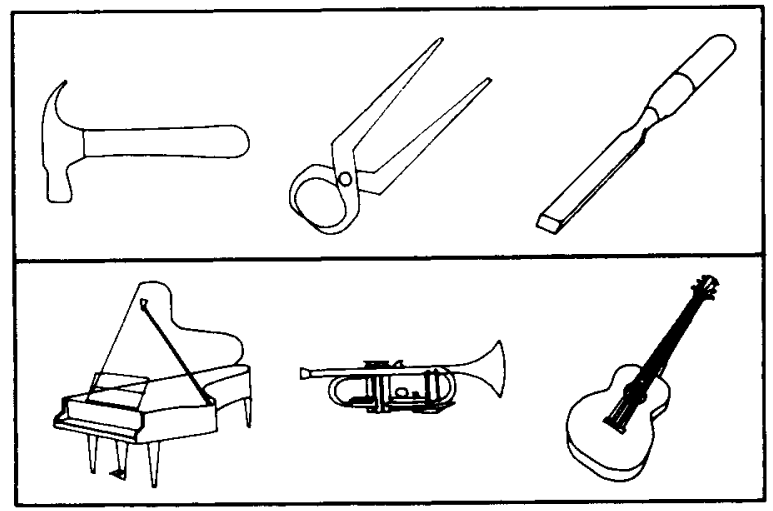

Figure 1. The six target pictures used in Experiment 1. 


\begin{tabular}{|c|c|c|c|c|c|c|}
\hline \multirow[b]{2}{*}{ Distractor: } & \multicolumn{6}{|c|}{ Target Picture } \\
\hline & GUITAR & HAMMER & VIOLIN & DRILL & SHAWL & $\mathbf{X X X X X}$ \\
\hline \multicolumn{7}{|l|}{$\begin{array}{l}\text { Characteristics of } \\
\text { distractor word: }\end{array}$} \\
\hline $\begin{array}{l}\text { Semantically related } \\
\text { to the picture }\end{array}$ & + & - & + & - & - & \\
\hline $\begin{array}{l}\text { Part of the response } \\
\text { set }\end{array}$ & + & + & - & - & - & \\
\hline $\begin{array}{l}\text { Member of a relevant } \\
\text { semantic category * }\end{array}$ & + & + & + & + & - & \\
\hline Condition Label: & REL/RS & UNR/RS & REL/NRS & UNR/NRS & IRR & CONTR \\
\hline
\end{tabular}

Figure 2. Examples of the six target-distractor combinations used in Experiment 1 and their characteristics. The presence $(+)$ or absence $(-)$ of the corresponding characteristic is indicated. *The relevant semantic categories were musical instruments and tools.

to the picture but was not part of the response set). In the fourth condition, the distractor denoted a member of the alternative semantic category that was not one of the targets in the experiment (e.g., the picture of a trumpet with the word DRILL). This condition will be referred to as UNR/NRS (unrelated/not in response set; i.e., the word was unrelated to the picture and was not part of the response set).

Note that these four conditions (REL/RS, UNR/RS, REL/NRS, and UNR/NRS) are orthogonal combinations of the semantic relatedness and response set membership factors. Furthermore, as indicated in Figure 2, the distractor words in the first four conditions denoted members of semantic categories that were relevant in a task in which musical instruments and tools were to be named. In the fifth condition, however, the distractor word denoted a member of a third, irrelevant, semantic category (e.g., the picture of a trumpet with the word SHAWL). This condition will be referred to as IRR (irrelevant). In the sixth condition, the distractor was a string of four, five, or six Xs. This condition will be referred to as CONTR (control).

This experimental design allowed for the examination of four kinds of context effects. First, the effect of semantic relatedness was examined both when the distractor was part of the response set (REL/RS vs. UNR/RS) and when the distractor was not part of the response set (REL/NRS vs. UNR/NRS). Second, the effect of response set membership was examined both when the distractor was semantically related to the target (REL/RS vs. REL/NRS) and when the distractor was unrelated to the target (UNR/RS vs. UNR/NRS). Third, the effect of what will be called semantic relevance was examined by comparing the conditions UNR/NRS and IRR. These conditions differed in that the words in the UNR/NRS condition were part of one of the two relevant categories (musical instruments and tools), whereas words in the IRR condition were part of an irrelevant semantic category (clothes). Finally, the ef- fect of the mere presence of an irrelevant word was determined by comparing the conditions IRR and CONTR.

\section{Method}

Subjects. Seventeen students of the University of Leiden served as paid subjects in Experiment 1. All had normal or corrected-tonormal vision.

Materials. Three pictures were chosen from each of the semantic categories of tools and musical instruments. Care was taken to select pictures that did not show a high visual similarity to each other (see Figure 1). The distractor words were the six verbal labels of the pictures, three other members from each of the two target categories, and three members from the category clothes (see Table 1 for the English translations of the distractor words used). The distractor conditions were those discussed above and shown in Figure 2. In the REL/RS condition, a picture was never accompanied by its own verbal label; therefore, in all the other distractor conditions, one picture-word combination was omitted. For example, the picture of a chisel was never accompanied by the words BEITEL (CHISEL), GITAAR (GUITAR), BOOR (DRILL), VIOOL (VIOLIN), SCHOEN (SHOE), or by a string of six Xs.

In the selection of the distractor words, an attempt was made to meet the following constraints: (1) For each of the semantic categories, the words in the various distractor conditions were to be equal in length, familiarity, and imageability (see Lupker, 1979). The mean lengths of the letter strings in the REL/RS, UNR/RS, REL/NRS, UNR/NRS, IRR, and CONTR conditions were 5.0, 6.0, $5.0,5.0,5.0$, and 5.0 characters, respectively, for the semantic category of tools, and 6.0, 5.0, 5.0, 5.0, 5.0, and 5.0 characters, respectively, for the semantic category of musical instruments. For one of the distractor words (PIERCER), no imageability and familiarity values were available in the Dutch language. The mean familiarity values of the remaining words in the REL/RS, UNR/RS, REL/NRS, UNR/NRS, and IRR conditions were 7.6, 7.5, 7.1, 7.6, and 8.3, respectively, for the semantic category tools, and $7.5,7.6$, $7.6,7.1$, and 8.3 , respectively, for the semantic category musical instruments (De Vries, 1986). ${ }^{1}$ The corresponding imageability values were $6.72,6.67,6.24,6.59$, and 6.73 , respectively, for the semantic category tools, and $6.67,6.72,6.59,6.24$, and 6.73 , respectively, for the semantic category musical instruments (Van Loon-Vervoorn, 1985). ${ }^{2}$ (2) Preferably, all initial letters of the words were to be different. This constraint could not be perfectly met. Care was taken, however, that none of the words had 
Table 1

Target-Distractor Combinations Used in the Various Distractor Conditions of Experiment 1

\begin{tabular}{lllllll}
\hline & \multicolumn{7}{c}{ Distractor } & Condition \\
\cline { 2 - 7 } Picture & REL/RS & UNR/RS & REL/NRS & UNR/NRS & IRR & CONTR \\
\hline Hammer & CHISEL & GUITAR & DRILL & VIOLIN & SHOE & XXXXXX \\
& PINCERS & TRUMPET & PLANE & FLUTE & CAP & XXXX \\
Pincers & CHISEL & GUITAR & DRILL & VIOLIN & SHOE & XXXXXX \\
& HAMMER & PLANO & PIERCER & ORGAN & SHAWL & XXXXX \\
Chisel & HAMMER & PIANO & PIERCER & ORGAN & SHAWL & XXXXX \\
& PINCERS & TRUMPET & PLANE & FLUTE & CAP & XXXX \\
& & & & & & \\
Piano & GUITAR & CHISEL & VIOLIN & DRILL & SHOE & XXXXXX \\
& TRUMPET & PINCERS & FLUTE & PLANE & CAP & XXXX \\
Trumpet & GUITAR & CHISEL & VIOLIN & DRILL & SHOE & XXXXXX \\
& PIANO & HAMMER & ORGAN & PIERCER & SHAWL & XXXXX \\
Guitar & PIANO & HAMMER & ORGAN & PIERCER & SHAWL & XXXXX \\
& TRUMPET & PINCERS & FLUTE & PLANE & CAP & XXXX \\
\hline
\end{tabular}

Note-REL/RS $=$ related/in response set. UNR/RS $=$ unrelated/in response set. REL/NRS $=$ related/not in response set. UNR/NRS $=$ unrelated/not in response set. IRR $=$ irrelevant. $C O N T R=$ control.

the same initial letter as the verbal label of the accompanying picture (for the importance of the first letter, see, e.g., Lupker, 1982; Posnansky \& Rayner, 1977; Regan, 1978; and Singer, Lappin, \& Moore, 1975). (3) In the distractor conditions, REL/NRS and UNR/NRS pictures were not to be combined with words that denote objects that show a large visual similarity to the target picture. For that reason, the picture-word combinations violin-GUITAR and piano-ORGAN were not used.

The pictures were drawn on a vector display by means of an interactive drawing program (Glazenborg \& Schreuder, 1983). They were scaled and centered in an imaginary square with dimensions $4.4^{\circ} \times 4.4^{\circ}$ of visual angle. The picture could appear either above or below a central fixation point. The word or string of Xs appeared at the opposite position. The distance between the fixation point and the closest contour of the word was equal to the distance between the fixation point and the closest contour of the imaginary square in which the picture was centered $\left(0.2^{\circ}\right.$ of visual angle). The words subtended $2.0^{\circ}-3.5^{\circ}$ of visual angle. Viewing distance was approximately $65 \mathrm{~cm}$.

Apparatus. Stimuli were presented on a fast display screen (Vector General). Verbal naming latencies were measured by means of a voice key with an accuracy of $1 \mathrm{msec}$. Presentation and registration of reaction times (RTs) and errors were controlled by a PDP 11/34 computer.

Procedure. The subjects were run individually in a dimly illuminated room. At the start of the session, they were shown each of the six pictures and were told the corresponding names. The subjects acquainted themselves with the task in a series of 40 practice trials. The stimuli in the practice series were a random sample of the stimuli in the experiment proper, with the restriction that each target picture appeared approximately equally often. Each trial involved the following sequence: A dim fixation point (asterisk) appeared in the center of the screen. After a buttonpress, following an interval of $500 \mathrm{msec}$, the picture and distractor were shown for $150 \mathrm{msec}$. The subjects were told to ignore the word or string of $\mathrm{Xs}$ and to name the picture as fast as possible while retaining accuracy. After each trial, the experimenter entered a code into the computer to indicate whether the response was correct or false. A distinction was made between incorrect responses (wrong name, the initiation of a wrong name, or a hesitation sound like "eh") and voice key malfunctions.

Each session involved two blocks of 144 trials ( 6 pictures $\times 6$ distractor conditions $\times 2$ distractor words per condition $\times 2$ positions $\times 2$ replications). The stimuli were presented in random order, with the restriction that a target picture was never presented twice in succession. Each block was preceded by four warm-up trials, and each incorrect response was followed by a filler trial. The results of the warm-up and filler trials were not included in the analyses.

\section{Results}

To reduce the variance in the data, the following datatrimming procedure was used. First, RTs of incorrect responses and RTs longer than 1,500 msec were excluded. Next, for each subject, means and standard deviations $(S D s)$ for each of the six distractor conditions were calculated. RTs that deviated more than $3 S D$ s from their cell mean were excluded. The remaining RTs were used in the calculation of the means. The 1,500 -msec criterion, the 3-SD criterion, and the trials in which the voice key malfunctioned accounted for $1.08 \%, 1.16 \%$, and $1.43 \%$ of the data, respectively. Table 2 shows the mean RTs and percentages of errors in the six distractor conditions for each of the two semantic categories.

Table 2

Mean Reaction Times (RTs; in msec) and Percentages of Errors (\%E) in the Various Distractor Conditions of Experiment 1

\begin{tabular}{|c|c|c|c|c|c|c|c|c|c|c|c|c|}
\hline \multirow[b]{3}{*}{ Semantic Category } & \multicolumn{12}{|c|}{ Distractor Condition } \\
\hline & \multicolumn{2}{|c|}{ REL/RS } & \multicolumn{2}{|c|}{ UNR/RS } & \multicolumn{2}{|c|}{ REL/NRS } & \multicolumn{2}{|c|}{ UNR/NRS } & \multicolumn{2}{|c|}{ IRR } & \multicolumn{2}{|c|}{ CONTR } \\
\hline & RT & $\% \mathrm{E}$ & RT & $\% \mathrm{E}$ & RT & $\% \mathrm{E}$ & RT & $\% \mathrm{E}$ & RT & $\% \mathrm{E}$ & RT & $\% \mathrm{E}$ \\
\hline $\begin{array}{l}\text { Tools } \\
\text { Musical Instruments }\end{array}$ & $\begin{array}{l}790 \\
819\end{array}$ & $\begin{array}{l}3.9 \\
1.5\end{array}$ & $\begin{array}{l}780 \\
804\end{array}$ & $\begin{array}{l}1.0 \\
2.9\end{array}$ & $\begin{array}{l}767 \\
792\end{array}$ & $\begin{array}{l}2.2 \\
1.0\end{array}$ & $\begin{array}{l}750 \\
784\end{array}$ & $\begin{array}{l}0.7 \\
0.5\end{array}$ & $\begin{array}{l}739 \\
749\end{array}$ & $\begin{array}{l}2.5 \\
1.0\end{array}$ & $\begin{array}{l}691 \\
707\end{array}$ & $\begin{array}{l}0.5 \\
1.2\end{array}$ \\
\hline Mean & 804 & 2.7 & 792 & 2.0 & 779 & 1.6 & 767 & 0.6 & 744 & 1.7 & 699 & 0.8 \\
\hline
\end{tabular}

Note-REL/RS = related/in response set. UNR/RS $=$ unrelated/in response set. REL/NRS $=$ related/not in response set. UNR/NRS $=$ unrelated $/$ not in response set. IRR $=$ irrelevant. CONTR $=$ control. 
An overall analysis of variance (ANOVA) was conducted on the RT data, with semantic categories (tools vs. musical instruments) and distractor conditions as within-subjects factors. Significant main effects were obtained for semantic category $[F(1,16)=11.6, p<.01$; mean naming latencies for the semantic categories tools and musical instruments were $753 \mathrm{msec}$ and $776 \mathrm{msec}$, respectively] and for distractor condition $[F(5,80)=31.4$, $p<.001]$. The interaction between these factors was far from significant $(p>.60)$. A Duncan post hoc test conducted on the data of the six distractor conditions showed that the CONTR and the IRR conditions differed from all other conditions at the .05 level. Of the first four conditions shown in Table 2, only the difference between the REL/RS and UNR/NRS condition reached significance at the .05 level.

The REL/RS, UNR/RS, REL/NRS, and UNR/NRS conditions are orthogonal combinations of the factors of response set membership of the distractor and semantic relation between picture and word; therefore, a separate ANOVA was conducted on the data obtained in these four conditions, with semantic category as a within-subjects variable. Significant main effects were found for semantic category $[F(1,16)=10.0, p<.01 ;$ mean RTs were 772 and $800 \mathrm{msec}$ for the semantic categories tools and musical instruments, respectively], for semantic relation $[F(1,16)=5.2, p<.05$; mean RTs were 792 and $779 \mathrm{msec}$ in the REL and UNR conditions, respectively], and for response set membership $[F(1,16)=6.5$, $p<.05$; mean RTs were 798 and $773 \mathrm{msec}$ in the RS and NRS conditions, respectively]. None of the interactions reached significance (all $p s>.50$ ). Given the large number of constraints that had to be imposed on the stimulus material and the small number of target stimuli, no $\min F^{\prime}$ ratios were calculated.

Although the error percentages were small, they were subjected to a similar ANOVA. A significant main effect was found for the semantic relation factor $[F(1,16)=7.5$, $p<.05$; mean percentages of errors were 2.14 and 1.29 in the REL and UNR conditions, respectively]. The response set membership factor failed to reach significance $(p<.07$; the percentages of errors were 2.33 and 1.10 in the RS and NRS conditions, respectively).

\section{Discussion}

The results show that even when the task relevance factor was controlled and attempts were made to eliminate interference due to perceptual similarity, a semantic relation between the word and the picture hampered the naming of the picture. This finding is in accordance with semantic interference effects obtained in picture-word interference studies, but clearly at variance with the results obtained by Neumann (1980). We will return to this discrepancy in the introduction of Experiment 2.

Apart from the effect of a semantic relation between word and picture, three other types of context effects were examined. First, a significant difference was found between the mean naming latencies in the RS and NRS con- ditions. Words that were part of the response set showed a larger interference effect on the naming of a picture than words that were not part of the response set.

Second, a significant difference was obtained between the distractor conditions UNR/NRS and IRR. Apparently, distractor words that denoted members of the relevant semantic categories musical instruments and tools induced more interference than distractor words that denoted members of an irrelevant category.

Third, a significant difference was obtained between the IRR and CONTR conditions. This finding shows that words that were part of an irrelevant semantic category induced interference as compared to a series of Xs.

\section{EXPERIMENT 2}

The small semantic interference effect obtained in Experiment 1 is clearly not in accordance with the results of Neumann (1980). In a more orthodox variant of the Stroop task, he obtained a semantic facilitation effect when the number of semantic categories was increased. Two possible causes of this difference can be advanced. First, in Neumann's study, a color-naming task was mixed with a dot-counting task. Consequently, in each trial, subjects had to decide whether they should name the color of the colored line or count the number of black dots (they were not to count the number of colored lines or name the color of the dots). This decision itself conceivably was affected by the distractor word. The decision between color naming and dot counting might be facilitated by the presence of, respectively, a color word and a numeral.

The difference between our present results and those of Neumann (1980), however, might also be due to an insufficient control of visual similarity in our Experiment 1 . It could be argued that within-category similarity was larger than between-category similarity because the pictures in the two categories differed in their complexity or detailedness. For that reason, the stimulus material in Experiment 2 was modified and preliminary experiments were run to ensure equal within- and between-category similarity.

To ensure some generalizability of the findings, a new set of semantic categories (fruit vs. parts of the body, with parts of a house as the third, irrelevant, semantic category) was added to the set used in Experiment 1 (tools vs. musical instruments). Figure 3 shows the pictures used. The similarity between the six pictures in each set of semantic categories was determined in a preliminary experiment. Instead of collecting similarity ratings, we decided to use a speeded same-different judgment task. This decision was based upon the following considerations: First, because of the dissimilarity of the pictures, it proved to be extremely difficult for the subjects to give ratings of differences in similarity. Second, in a similarity judgment task, subjects would have had ample time to examine the pictures, and, therefore, their judgment might have been influenced by semantic similarity. Third, a same-different judgment task had the advantage that the presentation 

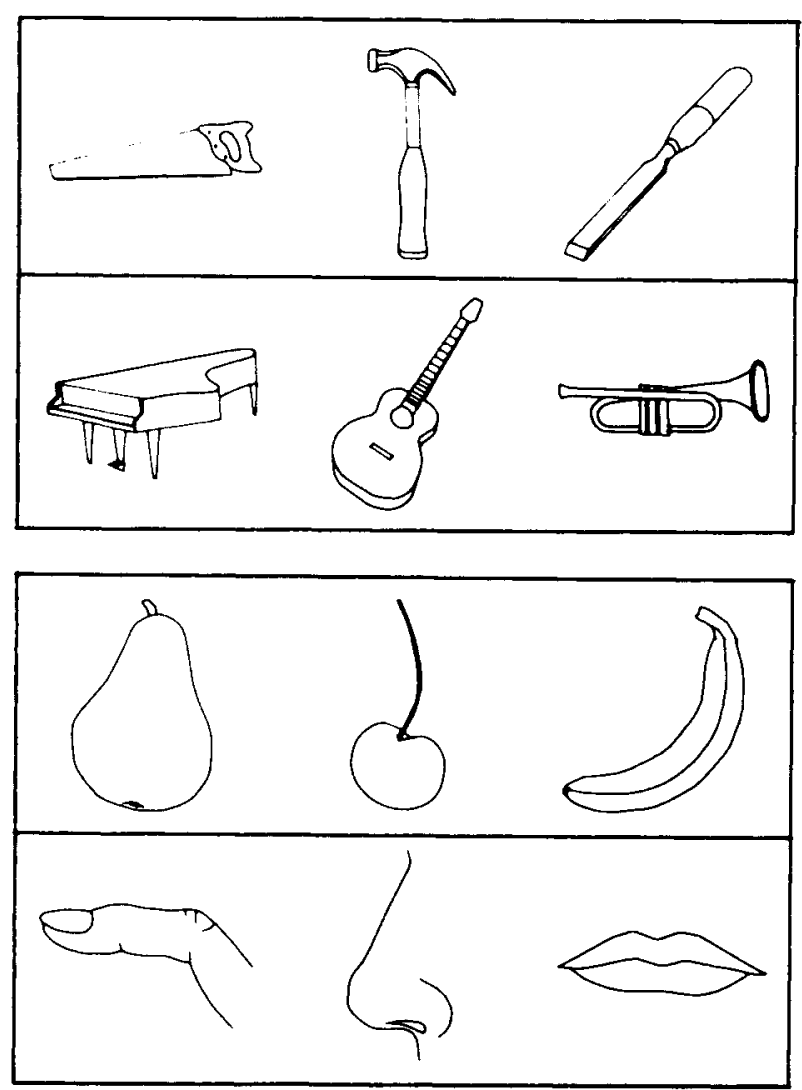

Figure 3. The target pictures used in Experiment 2. Upper panel: Set 1, musical instruments and tools. Lower panel: Set 2, fruits and parts of the body.

mode and presentation duration of the pictures could be identical to the ones used in the picture-word interference task.

In each trial of the same-different judgment task, two pictures were presented, one above and one below the central fixation point, at positions identical to those that were to be used in the picture-word interference task. In half of the 288 trials, the two pictures were identical to each other; in the other half of the trials, the pictures were different. The subjects had to indicate by means of a buttonpress response whether the pictures were identical or different. Sixteen subjects received the pictures from Set 1 (tools vs. musical instruments), and 16 other subjects received pictures from Set 2 (fruits vs. parts of the body). Mean correct RTs of the different trials were calculated for each of the six possible within-category comparisons (for Set 1: hammer-saw, hammer-chisel, saw-chisel, piano-trumpet, piano-guitar, guitar-trumpet) and for each of the nine possible between-category combinations (for Set 1: hammer-piano, hammer-guitar, hammer-trumpet, chisel-guitar, etc.). These mean RTs were taken to indicate the visual similarity between the pictures.

Because each picture in the picture-word interference task was combined with only two of the three possible distractor words in each distractor condition (see, e.g., Table 1), the mean RTs of three between-category combinations had to be omitted from the results of the same-different judgment task. By omitting the combinations piano-saw, guitar-hammer, and trumpet-chisel (Set 1), and finger-pear, nose-cherry, and mouth-banana (Set 2), approximately equal mean RTs for within- and between-category comparisons were achieved. The resulting mean RTs and percentages of errors are shown in Table 3. The corresponding picture-word combinations were omitted from the stimulus material to be used in the picture-word interference task (see Table 4). ANOVAs conducted on the mean RTs per subject showed that, for both sets of semantic categories, the three mean RTs in Table 3 do not differ significantly from each other (both ps > .30). Thus, if a difference were to be obtained between the conditions REL/RS and UNR/RS in Experiment 2 , it was unlikely that this difference could be attributed to a visual similarity between the picture and the picture denoted by the accompanying word.

Table 4 shows the English translations of the targetdistractor combinations used. Given the large number of constraints on the selection of the pictures and words, it proved to be impossible to match the three distractor words in each subset with respect to all relevant characteristics. For that reason, it was decided to equate the characteristic word length over the two semantic categories within each set. The drawback of this procedure was that a reliable comparison between the six distractor conditions could be made only after collapsing the data over the two semantic categories within each set. This drawback was another reason for including a second set of semantic categories in Experiment 2.

\section{Method}

Subjects. Thirty-two students of the University of Leiden served as paid subjects in Experiment 2. None had participated in Experiment 1. All had normal or corrected-to-normal vision.

Materials. Figure 3 shows the pictures, and Table 4 shows the picture-word combinations used. Picture-word combinations were

Table 3

Mean Reaction Times (RTs; in msec) and Percentages of Errors (\%E) in the Same-Different Judgment Task

\begin{tabular}{|c|c|c|c|c|c|c|}
\hline & \multirow{2}{*}{\multicolumn{2}{|c|}{$\begin{array}{c}\text { Set } 1 \\
\text { Within Category }\end{array}$}} & \multirow{3}{*}{$\begin{array}{l}\text { Between } \\
\text { Categories }\end{array}$} & \multicolumn{3}{|c|}{ Set 2} \\
\hline & & & & \multicolumn{2}{|c|}{ Within Category } & \multirow{2}{*}{$\begin{array}{l}\text { Between } \\
\text { Categories }\end{array}$} \\
\hline & Musical Instruments & Tools & & Fruits & Body Parts & \\
\hline RT & 472 & 479 & 474 & 468 & 466 & 461 \\
\hline$\% \mathrm{E}$ & 3.3 & 4.0 & 6.4 & 7.1 & 7.1 & 6.0 \\
\hline
\end{tabular}


Table 4

Target -Distractor Combinations Used in the Various Word Distractor Conditions of Experiment 2

\begin{tabular}{|c|c|c|c|c|c|}
\hline \multirow[b]{2}{*}{ Picture } & \multicolumn{5}{|c|}{ Distractor Condition } \\
\hline & REL/RS & UNR/RS & REL/NRS & UNR/NRS & IRR \\
\hline \multirow[t]{2}{*}{ Saw } & HAMMER & GUITAR & PINCERS & VIOLIN & SHIRT \\
\hline & CHISEL & TRUMPET & DRILL & FLUTE & TROUSERS \\
\hline \multirow[t]{2}{*}{ Hammer } & SAW & PIANO & PLANE & ORGAN & SHOE \\
\hline & CHISEL & TRUMPET & DRILL & FLUTE & TROUSERS \\
\hline \multirow[t]{2}{*}{ Chisel } & HAMMER & GUITAR & PINCERS & VIOLIN & SHIRT \\
\hline & SAW & PIANO & PLANE & ORGAN & SHOE \\
\hline \multirow{2}{*}{ Piano } & GUITAR & HAMMER & VIOLIN & PINCERS & SHIRT \\
\hline & TRUMPET & CHISEL & FLUTE & DRILL & TROUSERS \\
\hline \multirow[t]{2}{*}{ Guitar } & PIANO & SAW & ORGAN & PLANE & SHOE \\
\hline & TRUMPET & CHISEL & FLUTE & DRILL & TROUSERS \\
\hline \multirow[t]{2}{*}{ Trumpet } & GUITAR & HAMMER & VIOLIN & PINCERS & SHIRT \\
\hline & PIANO & SAW & ORGAN & PLANE & SHOE \\
\hline \multirow[t]{2}{*}{ Pear } & CHERRY & NOSE & GRAPE & EAR & DOOR \\
\hline & BANANA & MOUTH & LEMON & HAND & LOFT \\
\hline \multirow[t]{2}{*}{ Cherry } & PEAR & FINGER & APPLE & FOOT & WINDOW \\
\hline & BANANA & MOUTH & LEMON & HAND & LOFT \\
\hline \multirow[t]{2}{*}{ Banana } & PEAR & FINGER & APPLE & FOOT & WINDOW \\
\hline & CHERRY & NOSE & GRAPE & EAR & DOOR \\
\hline \multirow[t]{2}{*}{ Finger } & NOSE & CHERRY & EAR & GRAPE & DOOR \\
\hline & MOUTH & BANANA & HAND & LEMON & LOFT \\
\hline \multirow[t]{2}{*}{ Nose } & FINGER & PEAR & FOOT & APPLE & WINDOW \\
\hline & MOUTH & BANANA & HAND & LEMON & LOFT \\
\hline \multirow[t]{2}{*}{ Mouth } & FINGER & PEAR & FOOT & APPLE & WINDOW \\
\hline & NOSE & CHERRY & EAR & GRAPE & DOOR \\
\hline
\end{tabular}

Note-REL/RS $=$ related/in response set. UNR/RS $=$ unrelated/in response set. REL/NRS $=$ related/not in response set. UNR/NRS $=$ unrelated/not in response set. IRR $=$ irrelevant.

chosen on the basis of the same-different judgment task discussed above. With Set 1 , the highest and lowest mean decision times were obtained for the combinations trumpet-saw and guitar-piano, respectively. With Set 2, the highest and lowest mean decision times were obtained for the combinations nose-cherry and pear-finger, respectively.

To ensure some generalizability of the findings, one more set of semantic categories was added to the set used in Experiment 1. The mean length of the letter strings in the distractor conditions REL/RS, UNR/RS, REL/NRS, UNR/NRS, and IRR were 5.5, 5.5, 5.5, 5.5, and 5.0, respectively, in Set 1 (tools and musical instruments), and 4.7, 4.7, 4.7, 4.7, and 4.7, respectively, in Set 2 (fruit and parts of the body). The corresponding mean familiarity values were 7.6 , 7.6, 7.3, 7.3, and 8.4, respectively, for Set 1 , and 8.3, 8.3, 8.3, 8.3 , and 8.3 , respectively, for Set 2 . The corresponding imageability values were $7.76,7.76,6.48,6.48$, and 6.72 , respectively, for Set 1 , and $6.71,6.71,6.66,6.66$, and 6.73 , respectively, for Set 2 .

The display characteristics differed in a number of minor respects from those in Experiment 1. First, viewing distance was approximately $1 \mathrm{~m}$. Second, the words were presented at the point of fixation. The picture appeared above or below the word. The distance between the fixation point and the nearest contour of the imaginary square in which the picture was centered was $0.6^{\circ}$ of visual angle.

Procedure. Sixteen subjects received the stimulus material from Set 1; the other 16 subjects received the stimulus material from Set 2. At the start of a session, the six target pictures were presented simultaneously on the Vector General screen. The subject was asked to name them. In $6 \%$ of the cases, a name was given that was different from the one in Table 4 . In these cases, the subject was asked to adopt the names given in Table 4 . The experimenter explicitly mentioned that the six pictures were part of two semantic categories. Next, two practice series of 20 trials each were presented. In the first series, the target pictures were shown without distractors, and the subject was asked to name them as fast as possible while retaining accuracy. In the second series, picture-word combinations were presented, and the subject was told to ignore the word or string of Xs. In all further respects, the procedure was identical to the one in Experiment 1.

\section{Results}

The raw data were treated in the same way as in Experiment 1 . The 1,500-msec criterion, the 3-SD criterion, and the cases in which the voice key failed to trigger or triggered too early accounted for $.24 \%, 1.68 \%$, and .78\% of the data, respectively. The resulting mean correct RTs over subjects per set of semantic categories and distractor condition are shown in Table 5.

An ANOVA with sets of semantic categories as a between-subjects variable and distractor conditions as a within-subjects variable showed a significant main effect of sets $[F(1,30)=29.0, p<.001$; mean RTs were 736 and $634 \mathrm{msec}$ in Set 1 and Set 2, respectively], a significant main effect of distractor conditions $[F(5,150)=49.3$, $p<.001]$, and a significant interaction between sets and distractor conditions $[F(5,150)=2.6, p<.05$; see Table 5 for the corresponding means]. A Duncan post hoc test over the mean RTs obtained in the six distractor conditions averaged over sets of semantic categories revealed that only the 2-msec difference between the UNR/RS condition and the REL/NRS condition did not reach significance at the .05 level.

As in Experiment 1, a subsequent ANOVA was performed that included only the distractor conditions REL/RS, UNR/RS, REL/NRS, and UNR/NRS, with sets 
Table 5

Mean Reaction Times (RTs; in msec) and Percentages of Errors (\%E) in the Various Distractor Conditions of Experiment 2

\begin{tabular}{|c|c|c|c|c|c|c|c|c|c|c|c|c|}
\hline & \multicolumn{12}{|c|}{ Distractor Condition } \\
\hline & \multicolumn{2}{|c|}{ REL/RS } & \multicolumn{2}{|c|}{ UNR/RS } & \multicolumn{2}{|c|}{ REL/NRS } & \multicolumn{2}{|c|}{ UNR/NRS } & \multicolumn{2}{|c|}{ IRR } & \multicolumn{2}{|c|}{ CONTR } \\
\hline & RT & $\% \mathrm{E}$ & RT & $\% \mathrm{E}$ & RT & $\overline{\% E}$ & $\overline{\mathrm{RT}}$ & $\$ \mathrm{EE}$ & RT & \%E & RT & \%E \\
\hline $\begin{array}{l}\text { Set } 1 \\
\text { Set } 2\end{array}$ & $\begin{array}{l}764 \\
660\end{array}$ & $\begin{array}{l}4.4 \\
3.6\end{array}$ & $\begin{array}{l}759 \\
646\end{array}$ & $\begin{array}{l}2.7 \\
2.5\end{array}$ & $\begin{array}{l}750 \\
649\end{array}$ & $\begin{array}{l}3.1 \\
1.4\end{array}$ & $\begin{array}{l}747 \\
631\end{array}$ & $\begin{array}{l}1.8 \\
2.0\end{array}$ & $\begin{array}{l}711 \\
618\end{array}$ & $\begin{array}{l}1.8 \\
1.0\end{array}$ & $\begin{array}{l}683 \\
600\end{array}$ & $\begin{array}{l}1.2 \\
1.8\end{array}$ \\
\hline Mean & 712 & 4.0 & 702 & 2.6 & 700 & 2.3 & 689 & 1.9 & 664 & 1.4 & 642 & 1.5 \\
\hline
\end{tabular}

Note-Set 1: Musical instruments and tools. Set 2: Fruits and parts of the body. REL/RS = related/in response set. UNR/RS $=$ unrelated/in response set. REL/NRS $=$ related/not in response set. UNR/NRS $=$ unrelated/not in response set. IRR $=$ irrelevant. CONTR $=$ control.

as a between-subjects factor and semantic relation and response set membership as within-subjects factors. Significant main effects were obtained for sets $[F(1,30)=$ 29.1, $p<.001$; mean RTs were 755 and $646 \mathrm{msec}$ for Set 1 and Set 2, respectively], for response set membership $[F(1,30)=12.6, p<.01 ;$ mean RTs were 707 and $694 \mathrm{msec}$ in the RS and NRS conditions, respectively], and for semantic relatedness $[F(1,30)=6.2, p<.05$; mean RTs were 706 and $696 \mathrm{msec}$ in the REL and UNR conditions, respectively]. The interaction between the factors of semantic relation and response set membership was far from significant $(p>.90)$.

Although the percentages of errors were small, they were subjected to an identical ANOVA. Significant main effects were found for the factors of response set membership $[F(1,30)=9.5, p<.01$; mean percentages of errors were 3.32 and 2.08 in the RS and NRS conditions, respectively] and semantic relatedness $[F(1,30)=4.4, p<.05$; mean error percentages were 3.16 and 2.24 in the REL and UNR conditions, respectively].

\section{Discussion}

The results of Experiment 2 are essentially the same as those obtained in Experiment 1. Despite the fact that in Experiment 2 the semantic similarity and task relevance factors were unconfounded and visual similarity was controlled for, a semantic interference effect was obtained. The discrepancy between this finding and the result obtained by Neumann (1980) might be due to the fact that in Neumann's study a color-naming task and a dot-counting task were mixed. When subjects are uncertain which of these tasks to perform, a distractor word from one of the categories may facilitate this choice.

As in Experiment 1, the other three context effects also reached significance. First, the effect of response set membership (RS-NRS) shows that words that are part of the response set induce more interference than words that are not part of the response set. Similar findings have been obtained in the Stroop task (Proctor, 1978), in the picture-word interference task (La Heij \& Vermeij, 1987), in the letter identification task developed by C. W. Eriksen (e.g., B. A. Eriksen \& C. W. Eriksen, 1974; La Heij \& Vermeij, 1987), and in a word-word variant of the Stroop task used by La Heij et al. (1985). Of importance in the present series of experiments is the finding that this effect is independent of a semantic relation between dis- tractor and target. This finding is consistent with the lack of an interaction between the factors of response set membership and semantic relation in the word-word variant of the Stroop task reported by La Heij et al. (1985), and might indicate that these two distractor characteristics affect different processing stages.

The effect of semantic relevance (UNR/NRS - IRR) is in accordance with a similar finding reported by Neumann (1980, Experiment 5). It indicates that words that are unrelated to the target, but that are part of the two semantic categories from which the pictures are selected, induce interference more than do irrelevant words. This interference effect might be related to the interference effects reported by Warren $(1972,1974)$. In Warren's studies, it was shown that the naming of the color of a noncolor word (e.g., FUEL) was hampered when this word was semantically related to a to-be-memorized string of context words (e.g., OIL, GAS, COAL).

The interference effect defined as IRR-CONTR is a common finding in Stroop and picture-word interference tasks and can be due to the meaningfulness and/or the pronounceability of the letter string in the IRR condition (see, e.g., Bakan \& Alperson, 1967; Goodman, Haith, Guttentag, \& Rao, 1985).

The distractor conditions that correspond to conditions used in Klein's (1964) Stroop task show similar results; that is, interference decreases in the following order (the condition labels used by Klein are given in parentheses): REL/RS (F), REL/NRS (E), IRR (C), and CONTR (A). This finding corroborates Glaser and Düngelhoff's (1984) assumption that the same process underlies Stroop and picture-word interference.

\section{GENERAL DISCUSSION}

In previous Stroop and picture-word interference studies, the factor of semantic similarity between distractor and target has often been confounded with, respectively, the semantic relevance of the distractor and the visual similarity between the target picture and the object denoted by the word. In the present series of pictureword interference tasks, visual similarity was controlled and the factors of semantic similarity and semantic relevance were disconfounded. Under these conditions, a semantic relation between distractor and target still hampered the naming of the target. Thus, an interference ef- 
fect that is exclusively due to a semantic relation between distractor and target has now been firmly established in this type of task.

The experimental design used in the present study allowed the examination of three factors other than the effect of semantic relatedness: semantic relevance, response set membership, and the mere presence of a word. Under the prevailing conditions (a small set of target pictures drawn from only two semantic categories), all of these factors contributed significantly to the overall interference effect.

In Experiment 2, in which the target pictures were chosen from two semantic categories, the interference due to the semantic relevance of a distractor was more than twice as large as the interference due to the semantic similarity between distractor and target. The effect of semantic relevance probably will decrease with an increasing number of relevant semantic categories; therefore, the following conclusion seems warranted: In a Stroop-like task in which the targets are chosen from one semantic category (e.g., colors), the difference in interference between a distractor that is semantically related to the target but is not part of the response set (e.g., PURPLE in Klein's, 1964, study) and a distractor from an irrelevant semantic category (e.g., FRIEND in Klein's, 1964, study) is largely due to the semantic relevance of the color word distractor, and hardly due to the semantic relatedness between the color word and the accompanying color.

This conclusion might have important implications for the question of the locus of Stroop-like interference effects. Lupker and Katz (1981) distinguished four possible loci: (1) an input process, involving a basic perceptual analysis of the display; (2) a decision process, in which the relevant information is considered in order to make the decision demanded by the task; (3) a response selection process, in which an output code must be formed; and (4) a response output process. Lupker and Katz (1981) argued that interference due to the presence of an unrelated distractor word on the naming of a target picture is due mainly to interference in the response selection and response execution stages, but that the effect of semantic similarity should be localized at the decision level. Similar accounts of the semantic interference effect were given by Rayner and Springer (1986) and Seymour (1977). With respect to color-word interference, Seymour (1977) noted, "The principle involved here could be that delays of processing occur whenever distinct semantic codes are simultaneously activated, and that these delays become acute when the conflicting codes are values on a single dimension"' (p. 263).

This account of semantic interference, however, has a number of problems. First, as argued above, when the targets are chosen from a small number of semantic domains, a large part of the Stroop-like interference effect is due to the semantic relevance of the distractor in the task at hand and not to the semantic similarity between distractor and target. Second, the assumption of a semantic conflict seems hard to reconcile with a process of spreading activation between related concepts in a semantic domain. This process is proposed to account for semantic facilitation effects in priming studies (see, e.g., Carr, McCauley, Sperber, \& Parmelee, 1982; Hines, Czerwinski, Sawyer, \& Dwyer, 1986). Third, the assumption that the semantic interference effect is localized at the decision level does not seem in accordance with the disappearance of Stroop and picture-word interference effects in such non-naming tasks as scanning for a predefined color (Flowers \& Dutch, 1976; Uleman \& Reeves, 1971), sorting Stroop stimuli into bins according to ink color (Virzi \& Egeth, 1985), indicating ink color by means of buttonpress responses (McClain, 1983), matching the ink color of two Stroop stimuli (Egeth, Blecker, \& Kamlet, 1969), indicating the absolute position of an incongruent position word by means of a buttonpress response (Palef, 1978; Palef \& Olson, 1975; Virzi \& Egeth, 1985), and classifying geometric shapes or colors in the presence of incongruent names (Flowers \& Stoup, 1977).

The results of these studies seem to indicate that the semantic interference obtained in color- and picturenaming tasks should not be localized at a semantic decision level but at a level that has to do with the retrieval and/or production of a verbal naming response. In a similar non-naming task, Lupker and Katz (1981) asked subjects to indicate (by means of buttonpress or verbal yes/no responses) whether or not a target picture was the picture of a dog. In contrast to the studies mentioned above, a distractor word that was semantically related to the target picture hampered the identification of the picture more than did an unrelated word. This finding led Lupker and Katz to conclude that the semantic interference effect should be localized at the decision level.

In our view, however, Lupker and Katz's (1981) finding is open to an alternative interpretation. The targets chosen in their study (different pictures of dogs) form part of a semantic category (four-footed animals) with high intracategory visual similarity. In line with the arguments presented by Neumann and Kautz (1982), the interference effect obtained might be due to the perceptual similarity between the target pictures of dogs and animals denoted by the semantically related distractor words (e.g., CAT, HORSE, FOX, and LION).

As an alternative to the hypothesis that the semantic interference effect is localized at the decision stage, we propose that the effects of both semantic similarity and semantic relevance are localized at Lupker and Katz's (1981) stage of response selection. In picture-naming tasks, this is the stage of name retrieval. Two arguments in favor of this hypothesis can be advanced. First, the name retrieval hypothesis predicts that in Stroop and pictureword interference tasks, semantic interference effects will disappear when non-naming responses are required, provided that precautions have been taken to prevent interference due to the use of covert naming responses (for a discussion of this problem, see Dalrymple-Alford \& Az- 
koul, 1972) and to visual similarity between the picture and the object denoted by the word. As shown above, this prediction is confirmed in a substantial number of studies.

Second, if semantic interference effects are due to interference at a name retrieval stage, the prediction can be made that these effects will diminish or even disappear when name retrieval is facilitated. The results of name retrieval tasks with both normal speakers and aphasic patients suggest that facilitation of name retrieval can be achieved by providing such orthographic or phonemic cues as the first letter of the word to be found (see, e.g., Bowles \& Poon, 1985; Ellis, 1985; Gruneberg \& Monks, 1974; Lupker, 1982; Rayner \& Posnansky, 1978). The name retrieval hypothesis, therefore, predicts that semantic interference effects will diminish or disappear when the distractor word has orthographic or phonemic characteristics in common with the word to be retrieved.

This prediction is confirmed by recent results of Rayner and Springer (1986). They manipulated semantic similarity and graphemic similarity factorially in a picture-word interference task. The results showed that a 27 -msec semantic interference effect obtained in the graphemically dissimilar condition not only disappeared but even reversed into a 20 -msec semantic facilitation effect when the distractor word preserved the initial letter and word shape of the picture's label. For example, the semantically related word DRUM hampered the naming of the picture of a ball compared to the unrelated word PEAR, but the semantically related word BELL facilitated the naming of the picture of a ball more than did the unrelated word BILL.

We conclude that the name retrieval stage is a plausible candidate for the locus of the semantic context effects in Stroop and picture-word interference tasks. This conclusion implies that Stroop-like interference effects might be related to word retrieval impairments discussed in relation to the tip-of-the-tongue phenomenon (Brown \& McNeill, 1966; Jones \& Langford, 1987), to the effects of context on word retrieval upon the presentation of a definition (Brown, 1979), and perhaps even to some aphasic disorders (see, e.g., Ellis, 1985).

With respect to the mechanism involved, it could be argued that, in Stroop-like studies (including those of Brown, 1979, and Jones \& Langford, 1987), the size of the interference effect induced by a distractor word on name retrieval increases with the amount of priming the distractor word has received. This priming may be the result of a semantic relation between the distractor word and the task instructions (e.g., "in this experiment you have to name pictures of tools and musical instruments"), of a semantic relation between the distractor word and a to-be-memorized string of words (Warren, 1972, 1974), or of a semantic relation between the distractor word and the accompanying target (as in picture-word interference studies and the word retrieval study of Brown, 1979).
Neumann (1986) referred to this latter process as "reverse priming."

The effect of response set membership of the distractor word observed in the present study also may be localized at the name retrieval stage. However, given the findings that (1) this effect is easily obtained in tasks in which name retrieval is probably less problematic (as in the word- or letter-reading tasks of Flowers, 1980; Flowers \& Wilcox, 1982; La Heij et al., 1985; and La Heij \& Vermeij, 1987), and (2) the effects of response set membership and semantic similarity in our present experiments are additive, it is conceivable that response set membership affects such later processing stages as the choice between two available responses or the execution of one of the responses (see Coles, Gratton, Bashore, Eriksen, \& Donchin, 1985; and C. W. Eriksen, Coles, Morris, \& O'Hara, 1985).

In conclusion, we propose that the effects of semantic similarity and semantic relevance obtained in the present study are localized at the name retrieval stage. Interference in the identification of the target might be confined to situations in which the distractor denotes an object that is visually similar to the target.

\section{REFERENCES}

Bakan, P., Alperson, B. (1967). Pronounceability, attensity, and interference in the color-word test. American Joumal of Psychology, 80, 416-420.

Bowles, N. L., \& PooN, L. W. (1985). Effects of priming in word retrieval. Joumal of Experimental Psychology: Learning, Memory, \& Cognition. 11, 272-283.

Brown, A. S. (1979). Priming effects in semantic memory retrieval processes. Journal of Experimental Psychology: Human Learning d Memory, 5, 65-77.

Brown, R., MCNeill, D. (1966). The "tip of the tongue" phenomenon. Journal of Verbal Learning \& Verbal Behavior, 5, 325-337.

Carr, T. H., McCauley, C., Sperber, R. D., Parmelee, C. M. (1982). Words, pictures, and priming: On semantic activation, conscious identification, and the automaticity of information processing. Journal of Experimental Psychology: Human Perception \& Performance, 8, 757-776.

Coles, M. G. H., Gratton, G., Bashore, T. R., Eriksen, C. W., a Donchin, E. (1985). A psychophysiological investigation of the continuous flow model of human information processing. Journal of Experimental Psychology: Human Perception \& Performance, 11 , 529-553.

Dallas, M., Merikle, P. M. (1976). Semantic processing of nonattended visual information. Canadian Journal of Psychology, 30, 15-21

Dalrymple-Alford, E. C., Azkoul, J. (1972). The locus of interference in the Stroop and related tasks. Perception \& Psychophysics, 11, 385-388.

De VRIEs, K. L. M. (1986). Vertrouwdheid van woorden en woordherkenning [Familiarity of words and word recognition]. Nederlands Tijdschrift voor de Psychologie en haar Grensgebieden, 41, 295-304.

Egeth, H. E., Blecker, D. L., \& KAMLet, A. S. (1969). Verbal interference in a perceptual comparison task. Perception \& Psychophysics, 6, 355-356.

Ellis, A. W. (1985). The production of spoken words: A cognitive neuropsychological perspective. In A. W. Ellis (Ed.), Progress in the psychology of language (Vol. 2). Hillsdale, NJ: Erlbaum.

ERIKSEN, B. A., ERIKSEN, C. W. (1974). Effects of noise letters upon 
the identification of a target letter in a nonsearch task. Perception \& Psychophysics, 16, 143-149.

Eriksen, C. W., Coles, M. G. H., Morris, L. R., O'Hara, W. P. (1985). An electromyographic examination of response competition. Bulletin of the Psychonomic Society, 23, 165-168.

FLOWERS, J. H. (1980). Response priming effects in a digit naming task as a function of target-noise separation. Bulletin of the Psychonomic Society, 16, 443-446.

FLowER, J. H., \& DuTCH, S. (1976). The use of visual and name codes in scanning and classifying colors. Memory \& Cognition, 4, 384-390.

FLowers, J. H., \& StouP, C. M. (1977). Selective attention between words and colors in speeded classification and vocalization tasks. Memory \& Cognition, 5, 299-307.

FLOWERS, J. H., \& WILCox, N. (1982). The effect of flanking context on visual classification: The joint contribution of interactions at different processing levels. Perception \& Psychophysics, 32, 581-591.

Fox, L. A., Shor, R. E., Steinman, R. J. (1971). Semantic gradients and interference in naming color, spatial direction, and numerosity. Journal of Experimental Psychology, 91, 59-65.

Glaser, M. O., \& Glaser, W. R. (1982). Time course analysis of the Stroop phenomenon. Joumal of Experimental Psychology: Human Perception \& Performance, 8, 875-894.

GlaSER, W. R., \& DüNGELHOFF, F-J. (1984). The time course of picture-word interference. Journal of Experimental Psychology: Human Perception \& Performance, 10, 640-654.

GlazenborG, G., \& SCHREUder, R. (1983). Software tools for creating line drawings on a CRT. Behavioral Research, Methods \& Instrumentation, 15, 453-455.

Goodman, G. S., Haith, M. M., Guttentag, R. E., Rao, S. (1985). Automatic processing of word meaning: Intralingual and interlingual interference. Child Development, 56, 103-118.

GruneberG, M. M., \& MonKs, J. (1974). "Feeling of knowing"' and cued recall. Acta Psychologica, 38, 257-265.

Guttentag, R. E., \& Haith, M. M. (1978). Automatic processing as a function of age and reading ability. Child Development, 49, 707-716.

Hines, D., Czerwinski, M., Sawyer, P. K., Dwyer, M. (1986). Automatic semantic priming: Effect of category exemplar level and word association level. Journal of Experimental Psychology: Human Perception \& Performance, 12, 370-379.

JoNes, G. V., LANGFord, S. (1987). Phonological blocking in the tip of the tongue state. Cognition, 26, 115-122.

KLEIN, G. S. (1964). Semantic power measured through the interference of words with color-naming. American Joumal of Psychology, 77, 576-588.

La Hei,, W., Van der Heijden, A. H. C., \& Schreuder, R. (1985). Semantic priming and Stroop-like interference in word-naming tasks. Journal of Experimental Psychology: Human Perception \& Performance, 11, 62-80.

LA HeIJ, W., \& VermeiJ, M. (1987). Reading versus naming: The effect of target set size on contextual interference and facilitation. Perception \& Psychophysics, 41, 355-367.

LUPKER, S. J. (1979). The semantic nature of response competition in the picture-word interference task. Memory \& Cognition, 7, 485-495.

LUPKER, S. J. (1982). The role of phonetic and orthographic similarity in picture-word interference. Canadian Journal of Psychology, 36, 349-367.

LUPKER, S. J., KATZ, A. N. (1981). Input, decision, and response factors in picture-word interference. Jourmal of Experimental Psychology: Human Learning \& Memory, 7, 269-282.

MCClain, L. (1983). Effects of response type and set size on Stroop color-word performance. Perceptual \& Motor Skills, 56, 735-743.

NeumanN, O. (1980). Informationsselektion und Handlungssteuerung [Selection of information and control of action]. Unpublished doctoral dissertation, University of Bochum, Federal Republic of Germany.

Neumann, O. (1986). Facilitative and inhibitory effects of "semantic relatedness" (Report No. 111/1986). Bielefeld, Federal Republic of Germany: University of Bielefeld, Research Group on "Perception and Action."
Neumann, O., Kautz, L. (1982). Semantische Fördenung und semantische Interferenz im Benennungsexperiment [Semantic facilitation and semantic interference in a naming experiment] (Bericht Nr. 23/1982). Bochum, Federal Republic of Germany: University of Bochum.

PALEF, S. R. (1978). Judging pictorial and linguistic aspects of space. Memory \& Cognition, 6, 70-75.

Palef, S. R., Olson, D. R. (1975). Spatial and verbal rivalry in a Stroop-like task. Canadian Journal of Psychology, 29, 201-209.

Palmer, S. E. (1975). The effects of contextual scenes on the identification of objects. Memory \& Cognition, 3, 519-526.

PoSNANSKY, C. J., \& RAYNER, K. (1977). Visual-feature and response components in a picture-word interference task with beginning and skilled readers. Joumal of Experimental Child Psychology, 24, 440-460.

Proctor, R. W. (1978). Sources of color-word interference in the Stroop color-naming task. Perception \& Psychophysics, 23, 413-419.

RAYNer, K., Posnansky, C. (1978). Stages of processing in word identification. Journal of Experimental Psychology: General, 107, 64-80.

RAYNER, K., \& SPRINGER, C. J. (1986). Graphemic and semantic similarity effects in the picture-word interference task. British Journal of Psychology, 77, 207-222.

ReGAN, J. (1978). Involuntary automatic processing in color-naming tasks. Perception \& Psychophysics, 24, 130-136.

Rosinski, R. R. (1977). Picture-word interference is semantically based. Child Development, 48, 643-647.

Rosinski, R. R., Gounkoff, R. M., Kukish, K. S. (1975). Automatic semantic processing in a picture-word interference task. Child Development, 46, 247-253.

SEYMOUR, P. H. K. (1977). Conceptual encoding and locus of the Stroop effect. Quarterly Journal of Experimental Psychology, 29, 245-265.

Singer, M. H., Lappin, J. S., \& Moore, L. P. (1975). The interference of various word parts on color naming in the Stroop test. Perception \& Psychophysics, 18, 191-193.

STROOP, J. R. (1935). Studies of interference in serial verbal reactions. Journal of Experimental Psychology, 18, 643-661.

Uleman, J. S., \& ReEves, J. (1971). A reversal of the Stroop interference effect, through scanning. Perception \& Psychophysics, 9, 293-295.

UNDERWOOD, G. (1976). Semantic interference from unattended printed words. British Journal of Psychology, 67, 327-338.

VAN LOON-VERVOORN, W. A. (1985). Voorstelbaarheidswaarden van Nederlandse woorden [Imageability values of Dutch words]. Lisse: Swets \& Zeitlinger.

VIRZI, R. A., \& EGETH, H. E. (1985). Toward a translational model of Stroop interference. Memory \& Cognition, 13, 304-319.

WARREN, R. E. (1972). Stimulus encoding and memory. Journal of Experimental Psychology, 94, 90-100.

WARREN, R. E. (1974). Association, directionality and stimulus encoding. Journal of Experimental Psychology, 102, 151-158.

WARREN, R. E. (1977). Time and the spread of activation in memory. Journal of Experimental Psychology: Human Learning \& Memory, $3,458-466$.

Young, A. W., Ellis, A. W., Flude, B. M., McWeeny, K. H., \& HAY, D. C. (1986). Face-name interference. Journal of Experimental Psychology: Human Perception \& Performance, 12, 466-475.

\section{NOTES}

1. De Vries (1986) used a scale that ranged from 1 (very unfamiliar) to 9 (very familiar).

2. Van Loon-Vervoorn (1985) used a scale that ranged from 1 (very low imageability) to 7 (very high imageability).

(Manuscript received June 29, 1987; revision accepted for publication January 30,1988 .) 